 \\ International Journal of Social Sciences and Management
}

\section{A Rapid Publishing Journal}

ISSN 2091-2986

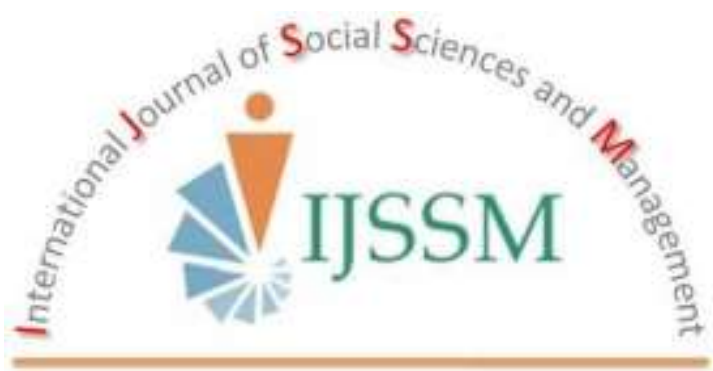

\section{Indexing and Abstracting}

CrossRef, Google Scholar, International Society of Universal Research in Sciences (EyeSource), Journal TOCs, New Jour, Scientific Indexing Services, InfoBase Index, Open Academic Journals Index (OAJI), Scholarsteer, Jour Informatics, Directory of Research Journals Indexing (DRJI), International Society for Research Activity (ISRA): Journal Impact Factor (JIF), Simon Fraser University Library, etc.

Vol-2(1) January, 2015

SEM-Biotech

Publishing

Impact factor ${ }^{*}: \mathbf{3 . 3 8 9}$ 


\title{
FACTORS THAT INFLUENCE THE PURCHASE AND CONSUMPTION OF ALCOHOLIC DRINKS IN MALAWI PARTICULARLY AMONG UNIVERSITY STUDENTS
}

\author{
Eliam Y.Z. Kamanga \\ Malawi National AIDS Commission, Malawi \\ Email for correspondence: eliamkamanga@gmail.com
}

\begin{abstract}
The purpose of this study was to explore the factors that influence the purchase and consumption of alcohol among university students in Malawi. The study sought to recommend strategies that can promote the marketing of alcohol among university students aged 18 and above. Results show that of the 138 respondents, 109 (72\% males and $28 \%$ females) agreed that they consume alcohol. The study indicates that quality of alcohol influences most students to consume alcohol. In addition, promotions that emphasise on price cuts and special offers have a positive impact on the marketing of alcohol among students. Notable also are subjective social norms which play a significant role in influencing students to consume alcohol with friends other than alone.
\end{abstract}

Key words: Alcohol consumption; Culture; Interpersonal factors; Marketing; Peer Pressure; Place; Product; Promotion

\section{Introduction}

The marketing of alcohol in Malawi has attracted use of the four (4) Ps of marketing namely product, price, promotion and place. This is so because marketing involves getting the right product at the right price in the right place (Hastings et al., 2005). Companies have also focused on different marketplace orientations in a bid to reach out to their target customers.

The first is the production concept. In this concept, the tendency has been to provide consumers with alcohol that is inexpensive and widely available. This has been the case because production companies have desired to expand markets for their products (Kotler, 2012).

Secondly, companies have focused on the Product Concept which suggests that consumers favour products that offer most quality, performance and innovative features (Kotler, 1999). In this concept, the focus has been on making superior products and improving them over time.

Thirdly, companies have embraced the selling concept which suggests that consumers and businesses if left alone won't buy enough of the company's products (Kotler, 2012). The aim has been to sell out what companies produce.

Companies have also embraced the marketing concept which is mainly consumer centered with the aim of producing different alcohol brands targeting different customers (Kotler, 2012).
While companies have put emphasis on different marketing approaches to reach out to consumers with alcohol, factors that affect actual purchase and consumption among Malawians especially university students have not been well researched. Consideration of the factors which actually affect consumer buying behaviour related to the purchase of alcohol among Malawians can help to design strategies that can help to improve the marketing of different brands of alcohol.

It is therefore, against this background that this study explored the factors that influence the purchase and consumption of alcohol among university students particularly from the Lilongwe University of Agriculture and Natural Resources (LUANAR). This is so because students have for a while provided a ready market for alcohol in Malawi and elsewhere despite the anti-alcohol campaign by World Health Organisation (WHO, 2011) and other advocates. It is expected that the findings of this study will assist marketers in Malawi to rethink and redesign their alcohol marketing strategies.

\section{Background to the study and problem statement}

Researchers have devoted considerable efforts in investigating factors that contribute to purchase and consumption of alcohol among university students. In the United States of America (USA), over $80 \%$ of college students drink alcohol (Johnston et al. cited in Ritter, 2008). In Malawi, according to the WHO Global Alcohol Database (2002) cited in Zverev (2008) the estimated amount of pure 
ethanol consumed per adult was 1.38 litres. This was lower than in South Africa, Zimbabwe, Zambia and Kenya (11.51, $3.91,2.92$, and 1.61 respectively).

Zverev (2008) pointed out that a considerable proportion of young adults in sub-Saharan Africa drink alcohol. Data shows that $54 \%$ of high school students in Lesotho consume alcohol. A survey done at the University of Ibadan in Nigeria revealed that $54 \%$ of freshmen drink alcohol. In Malawi, $72 \%$ of the students (78\% male and $63 \%$ females) reported alcohol consumption (Zverev, 2008). The same study revealed that commercial beer was the most preferred alcoholic drink among males (53\%) and females (36.2\%). There are a number of factors that offer an opportunity for alcohol to be a marketable product. First, students consider drinking alcohol as one of the most important things on campus (Student Monitor cited in Ritter, 2008). Secondly, a relationship exists between availability and consumption of alcohol. As availability increases, consumption also increases (Gruenewald et al. cited in Ritter, 2008). Thirdly, students have more disposable income than youth who are non-students (Ritter, 2008). With disposable income, students are likely to take part in drinking and start forming opinions about brand preferences. Fourthly, peer pressure plays a significant role on student alcohol consumption behaviour. This is so because students once selected to start university education transition from depending on their parents at home to depending on their peers in college (Orari and Carey, 2001 cited in Palmeri, 2011). Due to peer influence, new college entrants adopt the behaviour of their seniors in order to be accepted in the group with members of similar interests and behaviours. Other factors are culture, promotion, product attributes and situations under which alcoholic drinks are marketed.

Given the above background, literature on factors that influence the purchase and consumption of alcohol among Malawian consumers is hard to get. The scanty literature that is available has been documented in the context of substance and drug abuse and not necessarily on factors that influence individuals to purchase and consume alcoholic products. This may suggest that alcohol marketing strategies in Malawi have either been based on bare 4 Ps of marketing or on alien literature which may not suit the local marketing environment. It is for this reason that this study sought to investigate factors that influence the purchase and consumption of alcohol among Malawians and particularly, university students from LUANAR. It is hoped that the findings of this study will contribute towards generating literature that can help marketers and companies that trade alcoholic beverages to design marketing strategies based on local evidence.

\section{Specific research objectives and questions}

The overriding purpose of this study was to explore and explain factors that influence the purchase and consumption of alcohol among youth particularly university students from LUANAR. The study sought to examine different marketing strategies including the 4Ps of marketing, situational factors, subjective social norms, cultural factors, gender and age in order to ascertain if they contribute to influencing youth (students) to purchase and consume alcoholic drinks of their choice. Specific research objectives of the study were:

a) To explore the extent of alcohol consumption among students in Malawi;

b) To identify factors that influence alcohol consumption among students in Malawi; and

c) To examine how different marketing variables influence the purchase and consumption of alcohol among students in Malawi particularly from LUANAR.

\section{Research questions}

1) To what extent do students in Malawi consume alcohol as compared to other countries in the region and beyond?

2) What factors influence students to purchase and consume alcohol?

3) How do different marketing variables influence the purchase and consumption of alcohol among students from LUANAR?

4) Which variables are most important in influencing students to purchase and consume alcoholic beverages?

\section{Literature Review}

\section{Alcohol consumption in Malawi}

Literature on consumption of alcohol in Malawi is scanty. Literature that is available has been documented in the context of substance and drug abuse and not necessarily alcohol consumption let alone the factors that influence individuals to consume alcohol. Bisika, et al. (2004) conducted a rapid situation assessment on drug abuse and HIV/AIDS in Malawi which revealed that prevalence of alcohol consumption was $53.3 \%$ in the public, $38 \%$ in the tourism sector and $48.7 \%$ in the private sector.

Zverev (2008) conducted a survey of 787 University of Malawi students and found that about $72 \%$ of students $(78 \%$ males and $63 \%$ females) consumed alcohol. The study also found that commercial beer was the most preferred alcohol among students (52.3\% males and $36.2 \%$ females). Only $9 \%$ males and none among females reported consumption of traditionally brewed alcohol or spirits as their preferred alcohol (Zverev, 2008).

In 2011, WHO reported that the percentage of students who drank at least one drink containing alcohol on one or more of the past 30 days in Malawi was $5.3 \%$ for boys and $2.5 \%$ for girls. This was lower than the rates in other countries in the sub region who participated in the survey. For instance, Zambia had the rate of $38.7 \%$ among boys and $45.1 \%$ among girls. 
In view of the above account several factors influence alcohol consumption in Africa and Malawi. Among others, they include: socio-cultural factors, personality, religion, beliefs, attitudes, motivation, structural factors (e.g. availability), interpersonal relationships, media and marketing (Pettigrew and Donovan, 2003).

Zverev (2008) narrated: "traditionally, drinking was not part of the everyday life in African communities. However, during the second part of the last century, a pattern of sporadic drinking changed to a pattern of frequent heavy drinking, which was reflected in increased levels of alcohol consumption in sub-Saharan Africa". He argued that this transformation of drinking habits could be attributed to a combination of effects of several environmental, cultural, economic and social factors. In addition, Zverev (2008) pointed out that industrialization and urbanization stimulated alcohol consumption in rural areas due to the diffusion of drinking habits from towns to villages. Further, he argued that mass unemployment, poverty, erosion of the traditional communities and values, breakdown of taboos related to age, rapid changes in national, gender and ethnic identities and spreading of western drinking styles are some of the factors which contributed to alcohol consumption among the youth in sub-Saharan Africa (Zverev, 2008).

The above literature could be challenged on two grounds. First, it states that diffusion of drinking habits to rural areas might have led to increased consumption of alcohol in those areas. It is not clearly stated how this diffusion led to the adoption of the drinking behaviour. In the theory of diffusion of innovations, there are different levels at which consumers adopt a new behaviour. Zverev (2008) could have done justice had he explained exactly how the diffusion led to increased alcohol consumption by rural communities. Secondly, it is not well justified how exactly the breakdown of taboos related to age, gender and ethnic identities led to increased alcohol consumption among rural communities in sub-Saharan Africa. Nevertheless, his findings are handy in understanding some of the factors that influence alcohol consumption among individuals.

In South Africa, it was found that people including youth drink for several reasons including the following: drinking alcohol is acceptable; alcohol is a stress reducer; drinking is a means of dulling the pain of poverty; drinking is considered a "macho" behaviour; and drinking is associated with societal rituals (Freeman and Parry, 2006).

In Malawi, some of the above reasons probably apply. For example, among the Ngoni tribe, alcohol consumption is not a strange thing among both males and females. In addition, religion plays a vital role in as far as alcohol consumption is concerned. For instance, amongst Catholics, alcohol drinking is tolerated while in other Christian churches it is abhorred. Among Muslims, alcohol consumption is against the Islamic teaching.

\section{Specific Factors that Influence Alcoholic Consumption among Students}

\section{Price of alcohol and income}

In a study by Levy and Sheflin (1985) cited in Ritter (2008) it was pointed out: "pricing strategies have been used on assumption that as price decreases, consumption increases". However, in a study conducted by Nicola Stephenson to analyse the effects of price changes and alcohol content changes on behaviour intentions among students in Australia and New Zealand, it was concluded: "students were happy to pay higher prices for the same number of drinks and would simply buy more if the strength of alcohol was reduced" (Stephenson, 2012). The study went on to observe that when the cost was increased up to $25 \%$ there was still no significant change on consumer buying behaviour among students. This may suggest that there are other factors that affect the purchase of beer among students other than the price.

Christie et al. (2001) found that advertisements in local bars focused more on deep price discounts and special theme nights such as ladies' nights; beat the clock specials; any coin any drink; and "penny" beers. Their study concluded: "not surprisingly, lower prices generally lead to more favourable attitudes and intentions and increase the perceived likelihood of increased consumption" (Christie $e t$ al., 2001). This suggests that special offers such as price discounts rather than overall advertisements have a positive impact on the purchase of alcohol.

Christie et al. (2001) used the acquisition-transaction utility theory to hypothesize the effects of beverage promotion and its time frame influence on consumers' attitudes and intentions. The theory states that the acquisition utility is the economic gain or loss one gains from the transaction on a particular product or service. This is equal to the amount by which the utility of the purchased good or service exceeds the purchase price. The theory further states that the transaction utility is equal to the internal consumer's reference price less the purchase price of the product or service (Christie et al., 2001).

Thus, promotions which substantially reduce the price of a product, increases the acquisition utility by reducing the purchase price. This, therefore, improves perceptions of the economic gains in the consumer's mind. The reduced price also increases the transaction utility by reducing the purchase price relative to the consumer's reference price for alcohol (Christie et al., 2001). This motivates the consumer to purchase the product/service.

While the above discussion emphasises on the role of promotions in increasing consumption of alcohol, it is evident that the perceived price reduction plays a major role in improving the perception and attitudes of consumers towards a particular product. The author would like to contend that actually it is the impact of price discounts and not the actual advertisements associated with the lowering 
of the price and special offers that attract consumers to purchase alcohol and other products/services. The reduced price of a particular product is the one which attracts consumers to patronize the shop in large numbers and not necessarily the advertisements. Advertisements act as mere conduits for disseminating information about the product, price, quality and other attributes.

In view of gender dynamics, Christie et al. (2001) concluded that male and female non-students were expected to consume less alcohol than their male and female student counterparts, respectively. The high consumption among students was due to very low prices of alcohol. Suffice to mention that generally students unlike non-students have more income in form of pocket money from piece work and parents/guardians. With this income their propensity to spend part of the income on alcohol is high. On the other hand, non-students do not have any form of income and have nothing to spare on alcohol. In this case, when there are special offers like price cuts students are likely to consume more alcohol than when such offers are not available.

\section{Situational factors}

Situational factors may be defined as those aspects particular to time and place of observation which have an effect on behaviour (Ritter, 2008). Vazquez, et al., 2002 cited in Ritter (2008) has stated that consumers evaluate brands in different manners based on the situation. Consumers may purchase a commodity like alcohol based on where and when the purchase behaviour is occurring. According to research conducted elsewhere, around $80 \%$ of young people's total alcohol consumption takes place in public places (Knibbe et al., 1991 cited in Ritter, 2008). Furthermore, Wilks and Callan (1990) have concluded that the greatest occurrences of drinking are done in homes or bars. Also, happy hours in bars attracts consumers to buy and drink more beers (Ritter, 2008).

The learning environment in different colleges may affect alcohol consumption behaviour. Zverev (2008) observed that among the constituent colleges of the University of Malawi, the prevalence of alcohol consumption was higher at Chancellor College than College of Medicine and Kamuzu College of Nursing. He argued that this was due to different learning environments to the effect that the academic programme at Chancellor College (renown for partying) was less busy than in the other two colleges.

This suggests that a person may drink alcohol depending on a particular situation in which he finds himself. In Malawi, students are more likely to drink alcohol during events such as social weekends or parties. It is in such circumstances that peer influence creep in to influence non-drinkers to start drinking. By closely understanding such situations, marketing strategies can be well defined.

\section{Socio-cultural factors}

Mandelbaum (1965) has argued that among the great many substances that men have learnt to ingest, alcohol is by far culturally the most important. He has further asserted that in some languages such as English "the very term "drink" takes the connotation of drinking alcoholic liquids' (Mandelbaum, 1965). He has further claimed that alcohol is a cultural artifact that has form and meaning just as good as other major artifacts. For instance, drinking in a particular society may either be a sacred or profane act (Mandelbaum, 1965).

A good example of the role that alcohol plays in society may be drawn from Nigeria. Among the Kofyar people of Northern Nigeria "people make, drink, talk, and think about beer" (Netting, 1963 cited in Mandelbaum, 1965). However, other societies believe that beer is destructive and dispensable. For example, among the Hopi tribe in South West America, it was felt that drinking threatened their way of life. They thus abhorred use of alcohol to the extent of successfully banning its consumption (Mandelbaum, 1965). In religious circles, the Kofyar believed that man's way to god was with beer in the hand (Netting, 1963 cited in Mandelbaum, 1965). Also, the worshipers among the Aztecs of South America believed that at every religious occasion they had to get dead drunk. Otherwise, the gods would be displeased (Thompson, 1940 cited in Mandelbaum, 1965).

The above literature suggests that drinking has been popular even in historical times. It has been taken as part of rituals and the distinguishing feature between a sacred day and other days (Mandelbaum, 1965). This means that culturally in certain societies, alcohol consumption is part of a deeply entrenched cultural aspect.

According to Kotler and Keller (2012), "Marketers must, closely attend to cultural values in every country to understand how to best market their existing products and find opportunities for new products". If the culture of a particular society is well understood by marketers, they can target them with a product that they like. For instance, among the Ngoni of Malawi, it is often said that alcohol consumption is part of their culture. By understanding this fact, marketers can target the Ngonis with alcohol. While acknowledging Kotler's plea to pay attention to social cultural values when designing marketing strategies. Zverev (2008) has argued that among students with alcohol consumption behaviour, "binary logistic regression revealed that the year of study and tribe of responders did not have significant effect on pattern of drinking". Therefore, socio-cultural factors such as ethnicity should be used with caution when coming up with strategies on marketing of products.

Students, being part of different cultures and sub-cultures that exist in Malawi, have to be understood before targeting them with alcohol using a particular strategy. Needless to say that such being the case, there can be among student 
some who originate from a culture that permits alcohol consumption and can thus be targeted with alcohol brand of their choice.

\section{Gender and age}

In a study that was carried out among nursing school students in Bologna, Italy, alcohol intake was significantly related to sex (Bergamaschi, 1995). Wine drinking was more common among the males $(68.2 \%)$ than females $(56.8 \%)$. It was also found that the level of drinking among males increased with age (Bergamaschi, 1995). It was also found that the frequency of beer drinkers was significantly lower among the females $(61.8 \%)$ than males $(81 \%)$. In terms of drinking spirits, it was found that males $(33.8 \%)$ drank greater volume of spirits than females (20.8\%).

In Malawi, Zverev (2008) found that male students had a higher prevalence $(74 \%)$ of binge drinking compared to females $(27.4 \%)$. It has been argued that this drinking difference between Malawian male and female students could be explained partly by traditional African attitude towards women and their role in the family and society at large. Among men, alcohol consumption is considered a sign of maturity and wellbeing and it is generally tolerated. On the other hand, alcohol consumption by women is socially unacceptable because many traditional societies idealise women (Zverev, 2008).

According to Walsh and Mitchell (2005) cited in Ritter (2008), age and gender play a role in the way consumers evaluate and ultimately purchase alcohol. Also, males tend to drink heavily in groups of same sex, while ladies drink with mixed crowds or males (Hartford et al. 1983 cited in Ritter, 2008).

The foregoing account suggests that age and gender are variables worth investigating among university students in Malawi since elsewhere it has been established that they influence alcohol consumption. This is also important since girls and boys easily intermingle in colleges than elsewhere.

\section{Interpersonal factors}

In a study conducted in the United States of America (USA) it was found that over $80 \%$ of college students drank at least one alcoholic drink in a space of two weeks (Johnston, et al. cited in Palmeri, 2011). This behaviour was due to peer pressure "since college students must transition from depending on their parents at home to depending on their peers on college campus" (Borari and Carey, 2001 cited in Palmeri, 2011).

Peer pressure is the direct or indirect encouragement from one's own age group to engage in activities which s/he may or may not want to engage in (Palmeri, 2011). Peer influence is among the major factors that contribute to the development of behaviours such as alcohol consumption. Through modeling of such behaviours, students take alcohol use as a positive and socially accepted experience (Palmeri, 2011).
The above phenomenon can be understood better by closely looking at the social identity theory. According to Palmeri (2011), the social identity theory states that a significant part of a person's self-concept is formed through their peer groups, with the in-groups being regarded highly than the out-groups. In view of this, it is necessary for students to associate with the groups that are held in high regard (ingroups) than the out-groups in order to be accepted. Thus, those students who enter college as non-drinkers are likely to be considered as belonging to an out-group since they do not partake in the normative behaviour of alcohol consumption (Palmeri, 2011). In order to fit in with the ingroup, such students are likely to be influenced by friends to join and practice the behaviour of in-groups so that they are socially accepted. In this way, peer pressure can be regarded as one of the factors that affect consumer behaviour especially among young people.

The social identity theory can also apply to the Malawian situation since students are selected from diverse backgrounds and in order to match the behaviour of those considered to be superior they are thus influenced to experience the behaviour of the dominant groups. According to Pettigrew and Donavon (2003), peers are a major influence on how alcohol is drunk in terms of brand, type of alcohol, rate of consumption and even the associated amount.

Another theory that attempts to explain the importance of interpersonal relationships in influencing one's behaviour such as alcohol consumption among young people is Group Theory (Stafford, 1966). The theory suggests that group interaction is a major determinant in attitude formation, attitude change and satisfaction of social needs that are important to a person (Stafford, 1966). In this theory, groups may be defined as reference groups. Reference groups can mean a group to which a person belongs (membership group) or a group to which a person aspires to belong or a group to which he does not aspire to belong (dissociative group) (Stafford, 1966; Kotler and Keller, 2012).

Stafford (1966) has argued that reference groups are a source of a person's values, norms and perspectives. He has gone further to assert that reference groups influence behaviour in two ways. First, they influence aspiration levels and contribute to the achievement of satisfaction or frustration by a person. For example, if a member of a reference group is famous through his alcohol drinking behaviour, another person may be dissatisfied by his unpopularity. In this regard, s/he may mimic the behaviour of the popular friend in order to attain the popularity status. Secondly, reference groups may influence a particular behaviour among members. In this way, members are required to conform to that particular behaviour or dissociate themselves from the behaviour.

The theory, therefore, may also be applicable in alcohol consumption among students. This is so because peer 
pressure as outlined in the Social Identity Theory may lead a student who wishes to belong to a particular reference group (e.g. the drinking group) to copy the behaviour of other drinking members in order to conform to the drinking behaviour. This may thus in the long run determine the frequency and volume of alcohol a person consumes.

\section{Place}

The place mix is another "P" that should be considered when deciding on how to market a product. This variable relates to the distribution and availability of products and services at various outlets. According to Pettigrew and Donovon (2003), availability of alcohol in outlets is one of the important structural factors that affect consumption among youth. Availability issues which include the number of locations and outlets at which alcohol is purchased coupled with length of bar opening hours affect total alcohol sales (Jones et al.; Tatlow et al. cited in Pettigrew and Donovan, 2003).

The above literature suggests that availability of alcohol among young drinkers has an important role in their consumption behaviour. For example, because Coca Cola Company has realized that distribution of their product to many outlets increases the volume of sales, they have endeavoured to make their product accessible through many channels including supermarkets, milk bars, hotels, colleges and street vendors (Pettigrew and Donovan, 2003).

It is worth finding out if among students, the place factor has an impact on the purchase and consumption of alcohol in colleges like LUANAR. The striking feature of these colleges is that they have bars within the campuses. It is important to find out whether students like to frequent bars that are within the campus or those which are a distance away from the campus.

\section{Promotion}

Frankie and Wilcox (1987) concluded that there is no evidence of a significant relationship between total advertisement and consumption of beer but a significant relationship between consumption and advertisements of wine and distilled spirits. While noting that there was no significant relationship between total advertisement and beer consumption, proponents against use of alcohol by students think otherwise. They have wholly attributed alcohol abuse among students to advertisement (Frankie and Wilcox, 1987). In a survey conducted in the United States of America, it was found that students notice alcohol advertisements and especially like those that spotlight attractive people, make drinking look like fun, and feature attractive or exotic settings. It was also found that students exposed to beer commercials were more likely to think beer is "cool" or "macho" (Department of Health and Human Services, 1991).
To the contrary, in an experiment aimed at finding the effects of alcohol advertising on subsequent consumption, it was established: "No evidence was found that either lifestyle or tombstone advertising had any impact, immediate or delayed, on any category of alcohol consumption. Nor did subjects' evaluations of the types of advertisements differ significantly" (Kohn, Smart, and Ogborne, 1984: 34). Another study in the USA pointed out: "despite high advertising expenditure...the beer market has been losing market share" (US Market Leaders, 2007).

The above immediate assertion is supported by Frankie and Wilcox (1987) who states that alcohol advertisers contend that advertising does not increase overall consumption but leads to brand switching in a very competitive industry. Bourgeois and Barnes cited in Frankie and Wilcox (1987) also found little correlation between alcohol beverage advertising and per capita consumption of alcohol. The study concluded that alcohol consumption is influenced more by other uncontrollable variables than by those variables over which marketers and policy makers might exercise control.

In this present study, it is important to find out the role that advertisement play in the alcohol industry. What has been observed in the media in Malawi is the fact that advertisement predominantly focus on price discounts and other promotions such as happy hours and ladies night.

\section{Product}

"Product" is another strategy within the 4Ps of marketing that should be attended to if meaningful sales are to be realised. In this marketing concept, quality, design features, accessories, packaging, and variety of the product are emphasised by marketers or manufacturers (Kotler and Keller, 2009). The idea behind the product mix is to deliver a superior product/ service to the customer. In this strategy, it is important to position your product as either being superior or giving certain value to customers (Kotler and Keller, 2012). In this way, the product can be attractive on the market. In support of this, Brijball (2003) concluded: "quality followed by price are important general evaluative criteria but their importance diminishes when other product attributes are included". Therefore, in addition to the Product Mix other variables have to be attended to in order to benefit from the advantages that either of them offers to a marketer.

According Kotler and Keller (2009), much as the product strategy may assist in attracting consumers, it works well if well blended with the other 3Ps. For example, even if the product is of superior quality, it may not be readily sold if the price is too high or if it has not been fairly promoted. Therefore, the present study will try to find out if the product concept has an impact on the levels of purchase for alcoholic drinks in Malawi among university students. 


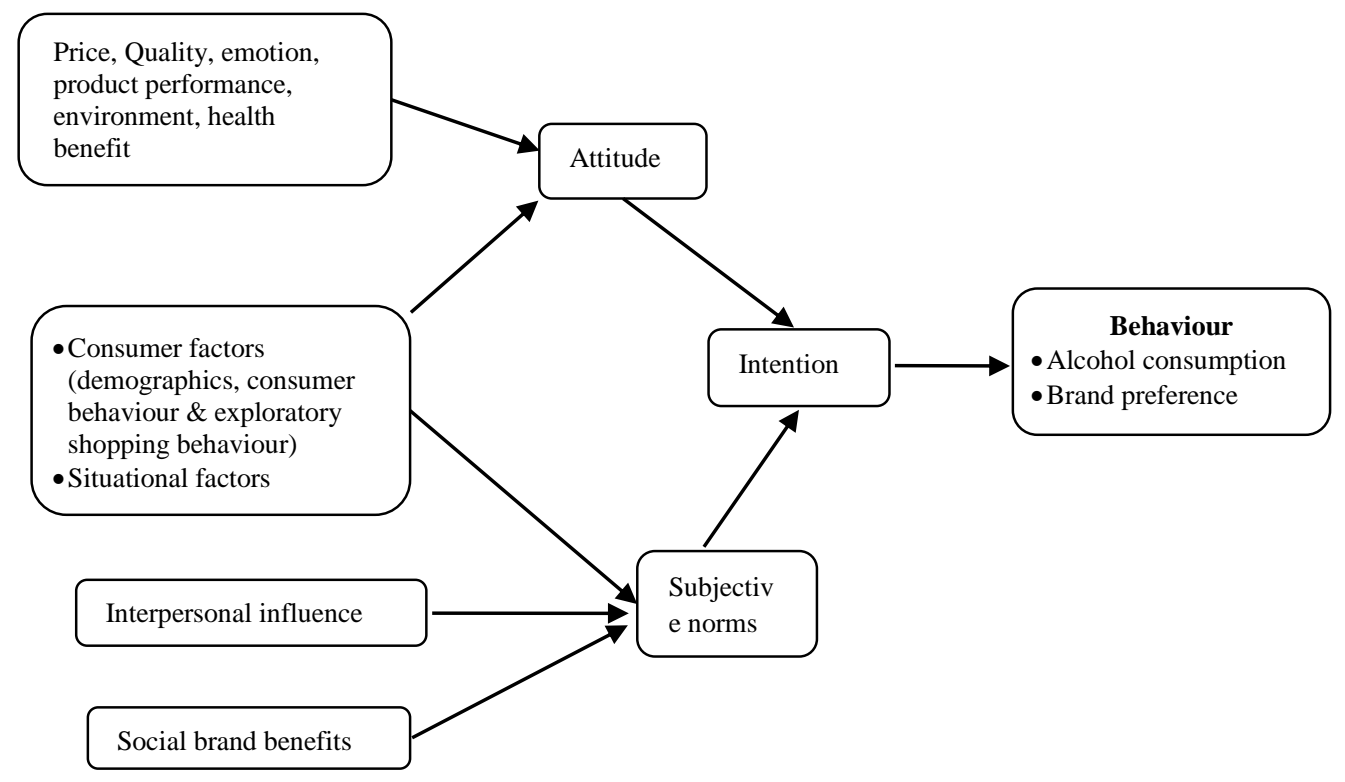

Fig. 1: Basic theory of reasoned action. Source: Adapted from Ritter, 2008; Vallerand et al., 1992.

\section{Theoretical Underpinnings for the Study}

\section{The theory of Reasoned Action}

This model has been used in many areas of study including marijuana, alcohol, and purchase of other consumer products (Eagly and Chaiken cited in Ritter, 2008). The theory suggests that behaviour is determined by the behavioural intention to emit the behaviour (Vallerand et al., 1992). The theory further states that there are two main factors that determine behavioural intentions namely: personal (attitudinal) and social (normative) (Vallerand $e t$ $a l .$, 1992). The first factor, (i.e. personal or attitude) towards a particular behaviour is considered to be a function of the salient behavioural beliefs about the perceived consequences of performing the behaviour and the person's evaluation of consequences of his/her performance of the behaviour (Vallerand et al., 1992).

The second factor, subjective norms, consists of an actor's perceptions of what important specific referent individuals or groups think s/he should do. In brief, subjective norms are a function of the person's normative beliefs regarding what each referent thinks s/he should do and the motivation to comply with the referents (Vallerand et al., 1992; Ritter, 2008). In this regard, normative and social influences have an impact on an individual's behaviour.

According to the theory (Fig 1), attitudes and subjective norms lead to an intention to perform a particular behaviour (Ritter, 2008). When one has an intention to do something, it means that there is a likelihood of completing a specific behaviour e.g. to consume alcohol which may results from personal or social influence (Ritter, 2008).

\section{Methodology}

A quantitative cross-sectional survey method was used in this research to propose reasons for particular relationships between variables (Saunders, et al, 2009). In addition, quantitative data was used to cancel out method effects eminent in both qualitative and quantitative approaches (Kulemeka, 2008; Saunders, et al, 2009).

The sample was drawn from (LUANAR) which caters for academically deserving students from all parts of Malawi. LUANAR has a total population of 2,526 students. The total number of respondents was one hundred and thirty one (131) with a precision of $10 \%$ and confidence limit of $5 \%$ at $95 \%$ confidence level (standard value of 1.96) and a design effect of one (1).

$$
n=\frac{t^{2} \times p q}{d^{2}}
$$

Where,

$q=1-p$

$\mathrm{n}=$ required sample size.

$\mathrm{T}=$ confidence level at $95 \%$ (standard value of 1.96 ).

$P=$ estimated proportion of students who drink. If proportion is unknown 0.5 was used.

$d=$ margin of error at $5 \%$.

Primary and secondary data was used to come up with the findings. One hundred and fifty (150) questionnaires were distributed to potential respondents to gather primary data. Most questions in the questionnaire employed the Likerttype rating scale with predetermined question and answer format (Saunders et al. cited in Kulemeka, 2008). Qualitative data was collected through two focus group discussions involving students.

A categorical data analysis technique was used to analyse data whereby all data sets were coded and categorized based on predetermined themes as contained in the questionnaire. The coded and categorised data was captured into SPSS and analysed through descriptive and non-parametric tests 
(Saunders et al., 2009). Qualitative data was analysed using content analysis technique to triangulate it with the quantitative data. Data was first categorized into groups of themes to which meanings were attached. This helped the researcher to draw conclusions which were triangulated with quantitative data (Saunders et al., 2009).

\section{Findings and Discussion}

\section{Consumption of alcohol among students at LUANAR}

Of the 138 respondents, $78.98 \%$ reported alcohol consumption. Twenty one point zero one percent $(21.01 \%)$ of the respondents reported that they do not consume alcohol. More males (72\%) than females (28\%) consume alcohol. Of those who reported alcohol consumption, $63 \%$ started drinking in Secondary School, 24\% started drinking in College and $13 \%$ started drinking at Primary School level. Most students might have started drinking alcohol in secondary school for various reasons. First, those who participated in FGD's cited independence from parents or guardians as one of the impetus to the adoption of the behaviour. One of the respondents stated:

"Since we are not under any parental control we think we can consume alcohol any time we feel like doing so" (FGD).

Secondly, they said that alcohol consumption is considered as a positive and socially accepted experience among peers. This is in line with the Social Identity Theory. In part, the theory states that a significant part of an individual's selfconcept is formed through interaction with peers whereby the 'in groups' are highly regarded than the 'out-groups'. In order to be accepted among peers students may tend to associate with the 'in groups' other than the 'out groups' (Palmeri, 2011). Assuming the members within the 'in groups' consume alcohol, new members are likely to be influenced to adopt the same behaviour so that they become identified with the group while at the same time becoming socially accepted.

\section{Alcohol consumption and year of study}

The year of study in which one is at a college may sometimes also have an influence on one's alcohol consumption behaviour. The Fig. 2 shows alcohol consumption among students in relation to their year of study.

Of the 109 respondents who reported alcohol consumption behaviour, 39\% were in third year. This was higher than in other years of study. When asked why this appeared so, respondents who took part in FGD's reported:

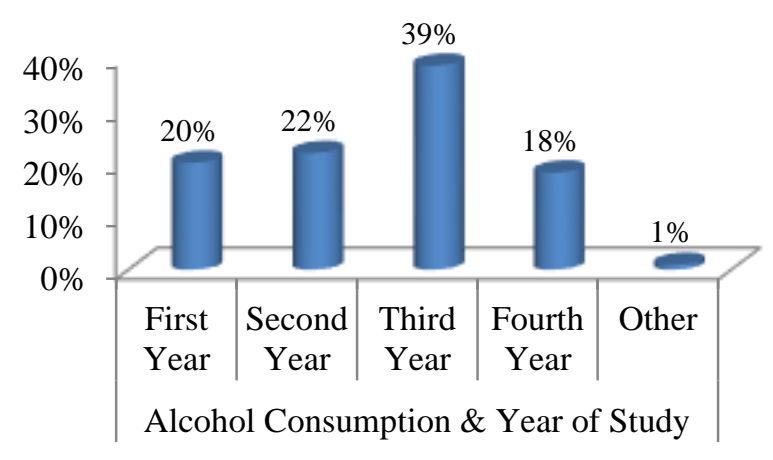

Fig. 2: Alcohol consumption and year of study

\begin{abstract}
"In third year, the academic programme is not tough as in other years of study. As a result of this there is more spare time to drink around. In fourth year, most students would want to graduate with a degree. As such, they tend to concentrate on studies more than drinking. In first year, many students are not sure of their studies. They fear being withdrawn from college if they fail. In such a way, they also tend to concentrate on studies than drinking alcohol" $(F G D)$.
\end{abstract}

This assertion is partly in line with what Zverev (2008) found among University Students in Malawi. He reported that students at College of Medicine and Kamuzu College of Nursing consumed less alcohol than their friends at Chancellor College because they have a learning goal orientation to the extent that the academic progrmme at Chancellor College was less busy than the other two colleges (Zverey, 2008).

\section{Specific Factors that Influence Students to Purchase and Consume Alcohol}

\section{Price and alcohol consumption among students}

Price may influence consumers to purchase products in a number of ways. Among customers, the Price represents the level of value that they ascribe to the item being bought (ABE, 2008). As such value changes from one person to the other. In this study, several variables within the Price Mix were examined to find out which ones could influence alcohol consumption among students. First, the price at which different alcohol brands are offered was examined in relation to the quality of alcohol. This was meant to find out the opinion of students as to whether the quality of the alcohol of their choice matches the price at which it is offered. Secondly, respondents were requested to suggest whether alcohol of their choice is economical. Thirdly, they were requested to state if alcohol brand of their choice offered value for money/price at which it is offered. Finally, they were requested to state if the price at which the alcohol was offered was reasonable. The Fig 3 shows how students responded to different variables patterning to the Price Mix. 


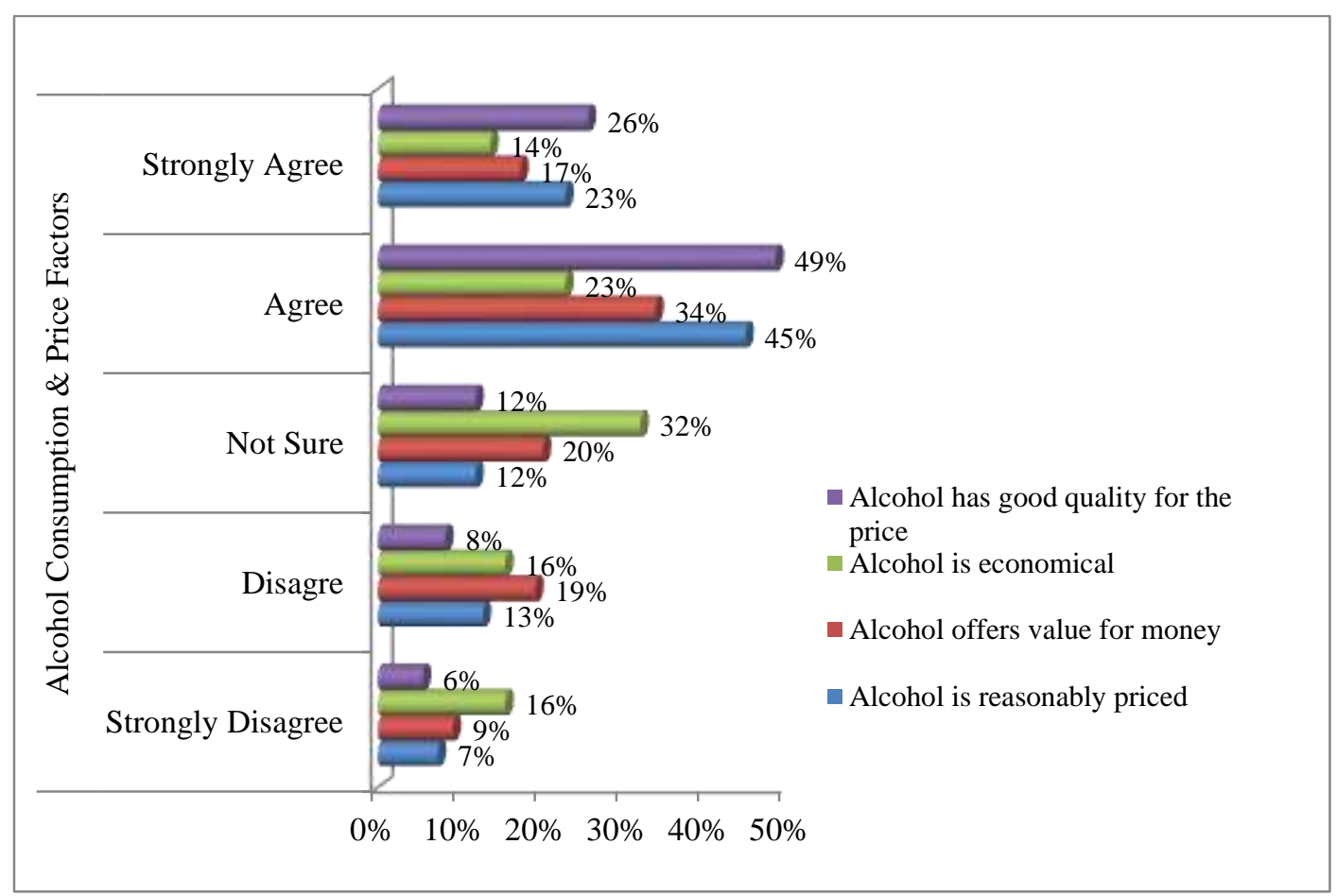

Fig. 3: Alcohol Consumption and Price Factors

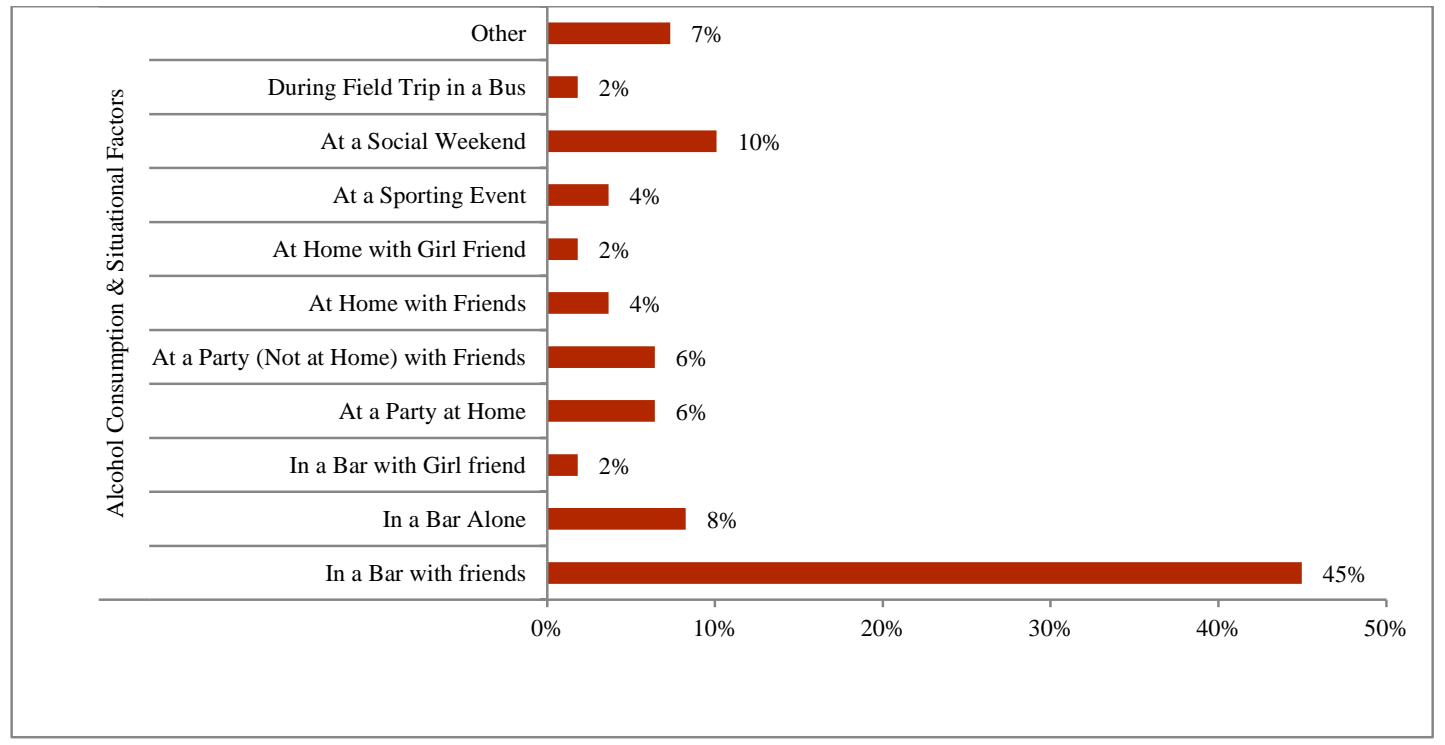

Fig. 4: Alcohol Consumption and Situation Factors

Most students (75\%) agreed that their brand of alcohol has a good quality for the price they pay. Furthermore, more than half of the students who reported alcohol consumption saw value for money in their preferred alcohol brands. Also, many students (78\%) agreed that their preferred alcohol brands are reasonably priced. However, $32 \%$ of the students were not sure whether or not the preferred alcohol brand is economical with respect to the prices offered.

The findings suggest that as long as the quality of alcohol is good and reasonably priced, students will be willing to purchase and consume it. According to ABE (2008), "There can be no doubt that there is direct correlation between price and quality. The better an item is, the more the customer will pay". Because of the perceived good quality of the alcohol brand of their choice, students are likely to relate quality of alcohol to the value for money they pay.

Furthermore, the findings have shown that price reasonability of the alcohol brand of choice can lead students to buy alcohol. In this case, students will among others weigh the price at which a particular alcohol brand is being offered before making the purchase decision. Thus, information search on different prices for alcohol will affect 
the manner in which students arrive at a decision to purchase particular brands.

Therefore, companies should strive to set prices in line with the quality of the product. In addition, the prices offered for the product should be reasonable to attract customers to purchase the product.

\section{Situational factors}

Situational factors refer to when and where alcohol is consumed or purchased. It might also refer to the environment under which alcohol is consumed or purchased (Ritter, 2008). Examples of situations under which alcohol may be consumed by students include social weekends, sporting festivals, parties and field trips. According to literature, such circumstances influence the consumption of alcohol among students. The Fig. 4 shows the percentages of student alcohol consumption under different situations. Of the respondents who reported alcohol consumption, $45 \%$ indicated that they like drinking with friends in bars. This is in line with what Knibbe et al., (1991) cited in Ritter (2008) found that $80 \%$ of young people's total alcohol consumption takes place in public places. However, this finding is contrary to what was found in the USA in a study that investigated where and how adolescents obtain alcohol where parties emerged as major sources of alcohol since alcohol prices were low during parties (Wagenaar et al., 1974). This difference might be due to the fact that students in the USA have a different upbringing from those in Malawi. In addition, parties are a frequent occurrence in the USA while in Malawi they are sporadic.

In Malawi, students like drinking in public places because of group interaction and in most cases they take turns in purchasing alcohol.
According to Stafford, (1996), group interaction is a major determinant in attitude formation, attitude change and satisfaction of social needs that are important to a person. In this regard, ones membership to a particular group with a specific behaviour such as alcohol consumption may influence him/her member to adopt that behaviour since the group values it to the extent that it is a norm.

\section{Cultural Factors}

Cultural factors that may influence consumer behaviour include traditional beliefs, religion, ethnicity, and social class. However, this study investigated the influence of religion, ethnicity and traditional beliefs on individuals' alcohol consumption behaviour. The Fig 5 shows the level of influence of cultural aspects on consumption of alcohol among students.

Religion, unlike other factors such as traditional beliefs and ethnicity, plays a significant role in influencing alcohol consumption among students. About $68 \%$ of the students agreed that they drink because it is permissible in their religion. About $74 \%$ disagreed that they drink alcohol because of their ethnicity and $36 \%$ disagreed that they drink because of their traditional beliefs. Hence, religion has a significant influence on alcohol consumption among students. This may be due to the fact that some religions such as Catholicism are not strict on alcohol consumption. However, this finding has some limitations since the study did not consider the impact of different religions on alcohol consumption.

The finding on ethnicity to the extent that about $74 \%$ disagree that they drink alcohol because of their ethnicity suggests that the influence of ethnicity on alcohol consumption among students is insignificant. However, the finding could also have some limitations in the sense that the study did not consider the extent to which students from different ethnic backgrounds consume alcohol.

\footnotetext{
"In bars, one enjoys drinking with friends and that friends can offer you free beers. You also chart and crack jokes. While if you drink alone, you don't enjoy because you have no one to talk to." FGD.
}

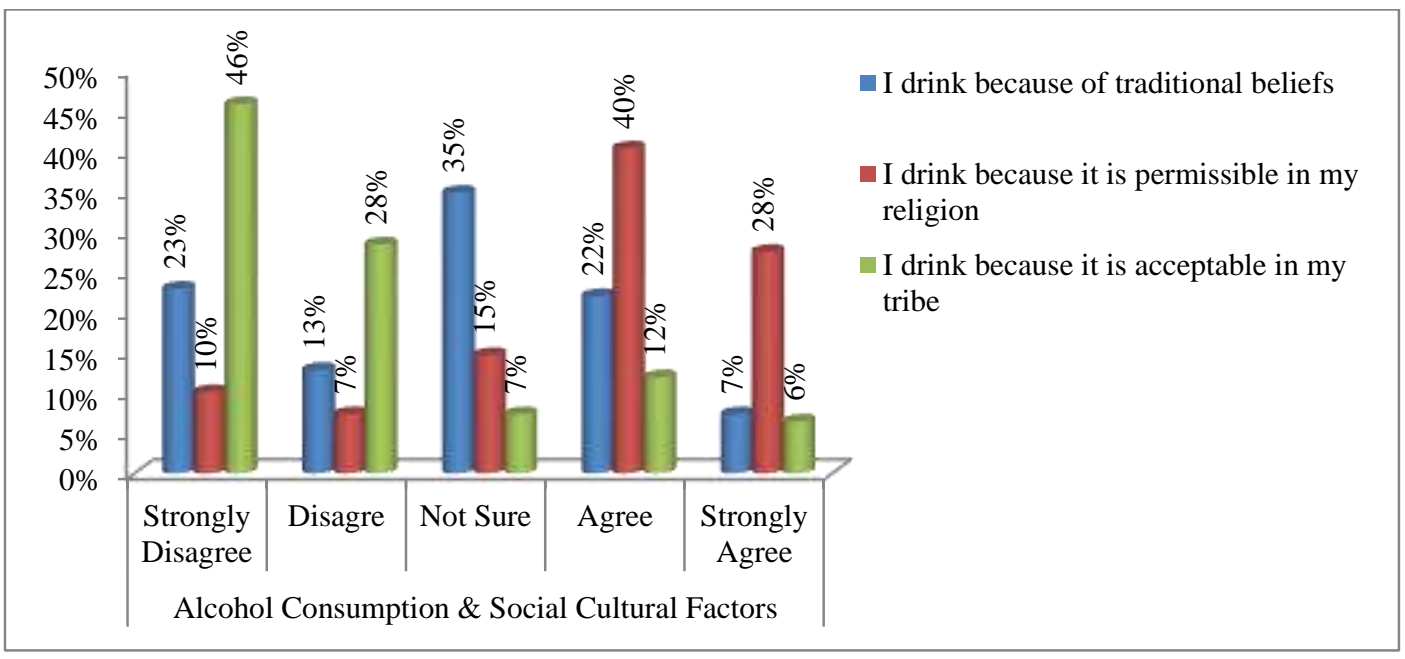

Fig. 5: Alcohol consumption and Cultural Factors 


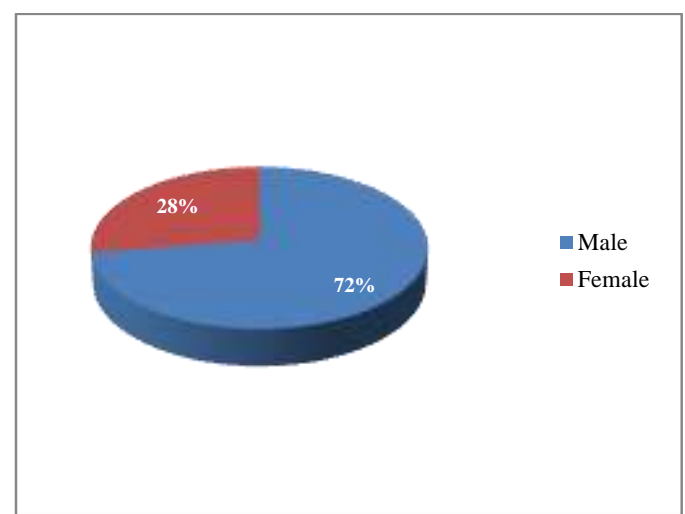

Fig. 6: Alcohol Consumption and Gender

\section{Gender and Age}

The Fig $6 \& 7$ below show alcohol consumption among students in relation to gender and age.

Fig. 6 shows that alcohol consumption is common in males (72\%) than in females (28\%). According to Zverey (2008), "the difference in alcohol consumption between Malawian female students and their male counterparts could be explained... by the traditional African attitude towards women and their role in family and society. While drinking among men is a sign of maturity and well-being and it is generally tolerated by families and societies, drinking of women is socially unacceptable". Zverey (2008) further states that in Nigeria women who abuse alcohol are considered as social misfits and in many cases end up in sex work due to rejection from their families.

Nonetheless, the labeling of women who abuse alcohol as social misfits seem misplaced since men also abuse alcohol and nothing happens to them. As such alcohol use among women should not mislead marketers to think that women are not the right target for their alcohol products. Given the gender dimension prevalent in the world, females should equally be considered when designing marketing strategies despite the social cultural stereotypes that portrays women as nondrinkers.

In terms of age, the larger proportion $(66 \%)$ of students who reported alcohol consumption is within the 18-22 age group. Most (63\%) started drinking while in secondary school. This is consistent with previous report found in the United States of America where most participants reported initiating drinking in high school. This phenomenon could be due to peer influence and group interaction since young students as they enter college transition from depending on parents at home to depending on their peers on campus (Borari and Carey, 2001 cited in Palmeri, 2011). Peer pressure thus directly or indirectly encourages young ones to easily adopt the behaviour of their dominant peers they find and interact with on campus since alcohol is taken as a positive and socially accepted experience among some segments of students (Palmeri, 2011).

The above discussion suggests that as student grow and as they transition in their academic life, they adopt new behaviours including alcohol consumption. This is partly because of peer influence and group interaction. Also since

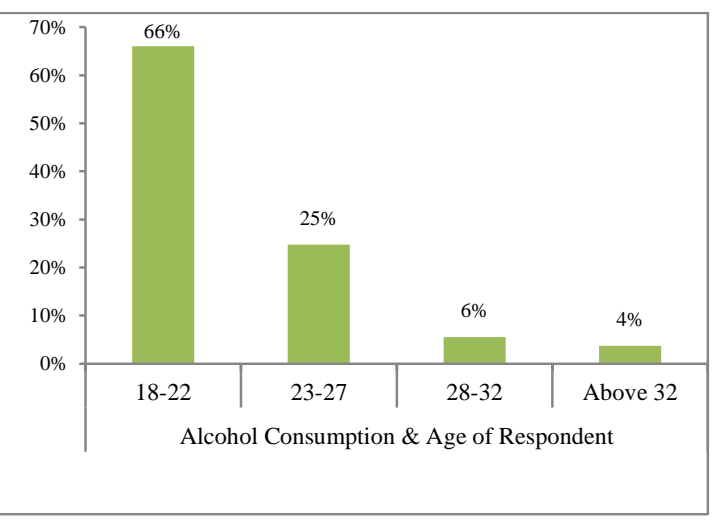

Fig. 7: Alcohol Consumption and Age they are now becoming independent, they are able to make decisions regarding alcohol consumption.

\section{Interpersonal Factors}

Interpersonal factors and subjective social norms that influence alcohol consumption among students includes peer influence, group influence and social interactions within similar age groups. The Fig 8 shows the influence of interpersonal factors on alcohol consumption among students in Malawi particularly LUANAR.

About $74 \%$ of the students who reported alcohol consumption agreed that alcohol consumption builds their confidence when interacting with peers. Furthermore, about $48 \%$ of the students agreed that alcohol consumption makes them socially approved and accepted by peers. However, some students disagreed that alcohol consumption improves the way they are perceived by peers. They also disagreed that alcohol consumption makes good impression on others.

The above findings show that interpersonal factors including peer influence encourage alcohol consumption on a good number of students since they feel that if they take alcohol they can confidently interact with peers and that they become socially accepted and approved. According to the Theory of Reasoned Action peer influence results in students accepting subjective social norms which lead to the adoption of alcohol consumption behaviour and brand choice among peers (Ritter, 2008; Vallerand et al., 1992). Also, according to the Social Identity and Group Theories, students originate from different backgrounds and in order to conform to the behaviours of students considered as superior (in groups), they copy behaviours such as alcohol consumption (Palmeri, 2011). They adopt such behaviours since they think that they are positive and socially accepted among peers. Hence, as students move away from depending on their parents at home, they start adopting new behaviours such as alcohol consumption in order to match the behaviours of fellow students with a similar behaviour.

\section{Place}

The Place element of the marketing mix relates to the actual location where a buyer can purchase a particular product such as alcohol. It is also concerned with the entire management of the distribution process. This means that it 
comprises all processes involved in getting the product or service to the buyer and ultimately to the end user in the most economical manner (ABE, 2008). Some of the activities involved in the Place element include order receiving and processing, stocking, transportation, delivery and display and making the products available to end users (ABE, 2008). In essence, the Place element refers to the availability of a product on the market. This availability can be achieved through a number of ways including strategic distribution through a number of outlets. In addition, the place factor can be effective if distribution covers a wider area where the target consumers are found. The distribution itself can be efficient if quicker methods of delivery to outlets are used.

In the case of this study, the Place element considered availability of alcohol on-campus and off-campus. Fig. 9 demonstrates the influence of the Place element on alcohol consumption among students on-campus. Fig. 10 shows the influence of the Place factor on alcohol consumption among students off-campus.

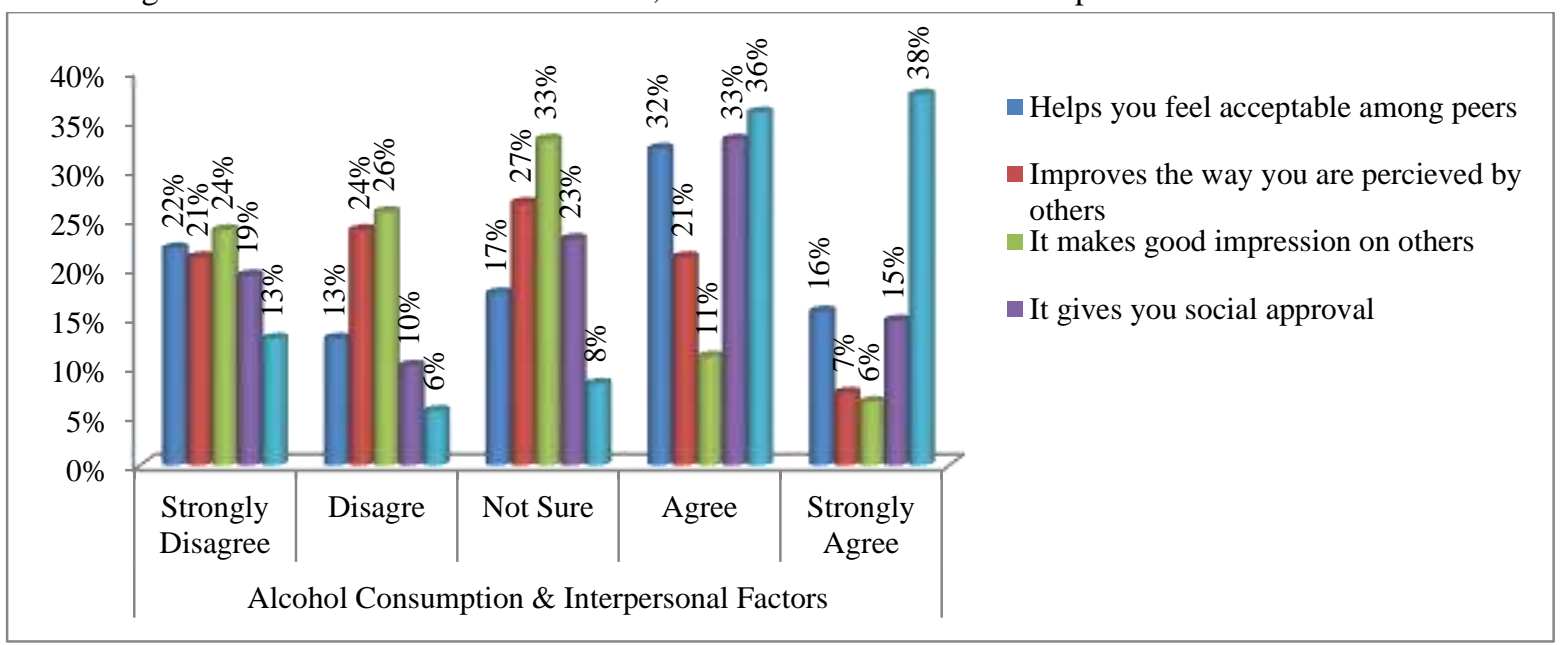

Fig. 8: Interpersonal factors \& alcohol consumption

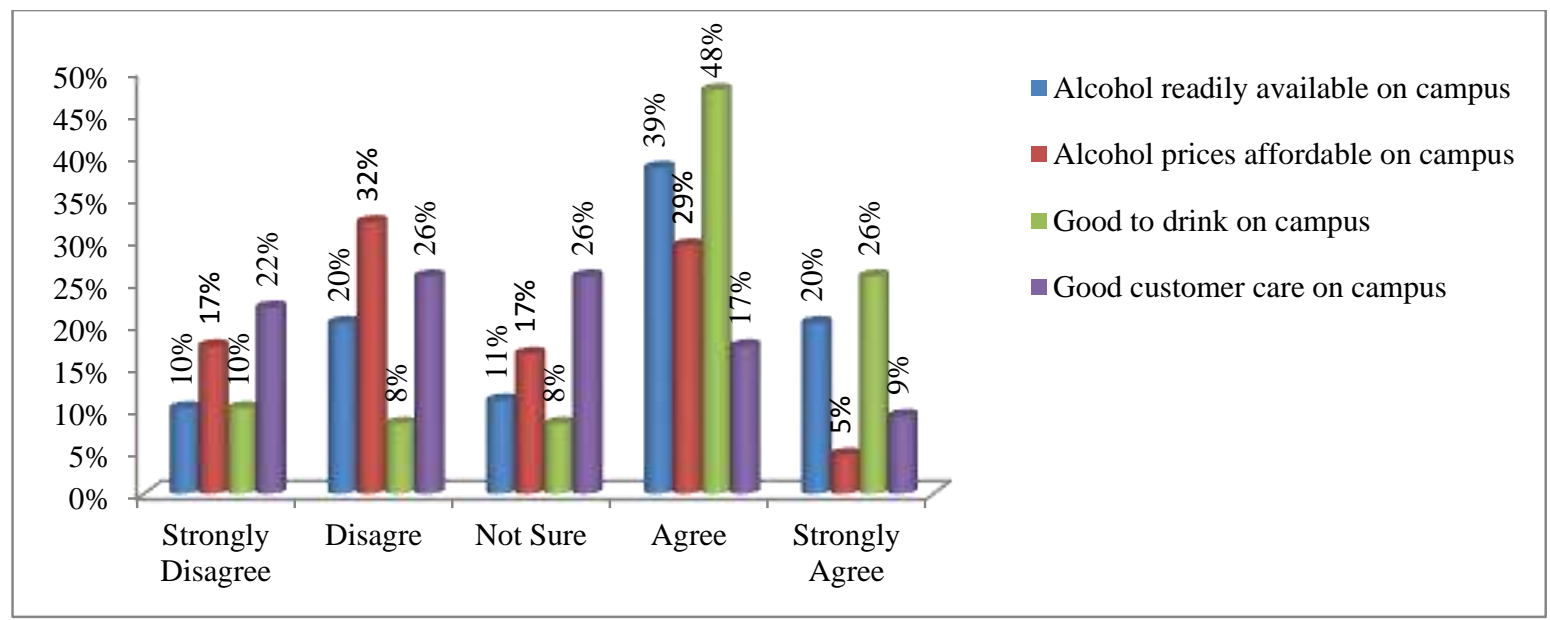

Fig. 9: Alcohol Consumption On-campus

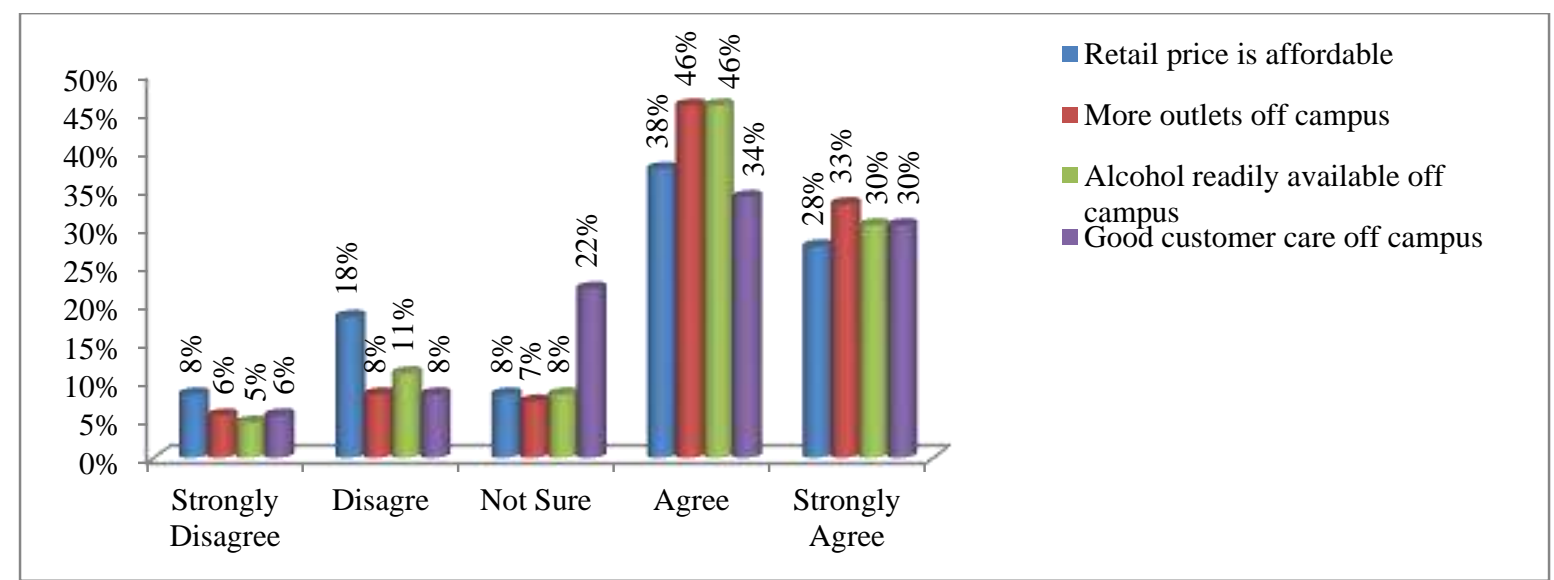

Fig. 10: Alcohol Consumption and Location factors off- campus 
Many students (74\%) reported that they enjoy drinking on campus since alcohol is readily available. On the other hand, some students $(49 \%)$ feel that alcohol prices on campus are not affordable given their little income, usually pocket and book allowance. In addition, $48 \%$ of respondents who reported alcohol consumption behaviour expressed reservations towards customer care by bar attendants on campus.

The above account suggests that much as students would want to consume alcohol right on campus, they might be deterred by poor customer care service from bar attendants and owners. Quality customer care is one of the quality service dimensions that can help to retain customers. Poor or inadequate customer care may scare away customers. This implies that much as alcohol may be available, other factors associated with provision of services to customers must be taken into account in order to grow, satisfy and retain customers.

Also, taking alcohol closer to where the target customers are can act as a motivation for them to enquire about the product leading to making a decision to acquire and use it. This may only work if other quality dimensions such as customer care, responsiveness to customer demands and timely provision of alcohol are adhered to. Apart from alcohol, FGD participants also reported that alcohol consumption on campus lacks some other important services such as music performance that provide entertainment to customers.

As highlighted in the above graph, students expressed satisfaction in relation to location factors off-campus. They agreed that alcohol prices are affordable off- campus probably because there are many outlets that sell alcohol and in an attempt to attract more customers, bar owners offer alcohol at relatively competitive prices coupled with satisfactory customer care to out-compete rivals.

The above findings suggest that it does not matter whether one distributes alcohol on-campus or off-campus. Students who consume alcohol can still access their alcohol brands of preference either on-campus or off-campus provided the service quality dimensions such as customer care are taken into account by bar owners. Respondents who took part in the FGD's had this to say:

\begin{abstract}
"For those of us who consume alcohol, we can purchase it either on campus or off-campus. There is a college bus that goes to town every day and we take advantage of the bus to go and consume alcohol in town where there are many drinking places than oncampus. In town, you can choose which bar to go to depending on the price of beer. Some bars target affluent people and hence prices for alcohol are high while others target ordinary people such that prices are affordable. On top of that, you can also have meat to eat unlike on-campus where meat is hardily provided. In town, you can also be entertained to music performed by live bands".
\end{abstract}

The above discussion implies that much as alcohol can be available in various outlets on-campus or off-campus, other factors such as customer care, price and other extras such as live performance by music artists should be offered to attract more customers.

\section{Promotion}

The Promotion Mix covers a range of activities involved in advertising, sales promotion, public relations, direct marketing and personal selling. Promotion plays a significant role in informing consumers about a product that is on the market. This study considered variables including advertisement, sales persons, special promotions and celebrity endorsement.

The Fig 11 shows the level of agreement/disagreement towards the factors under the promotion Mix that were researched.

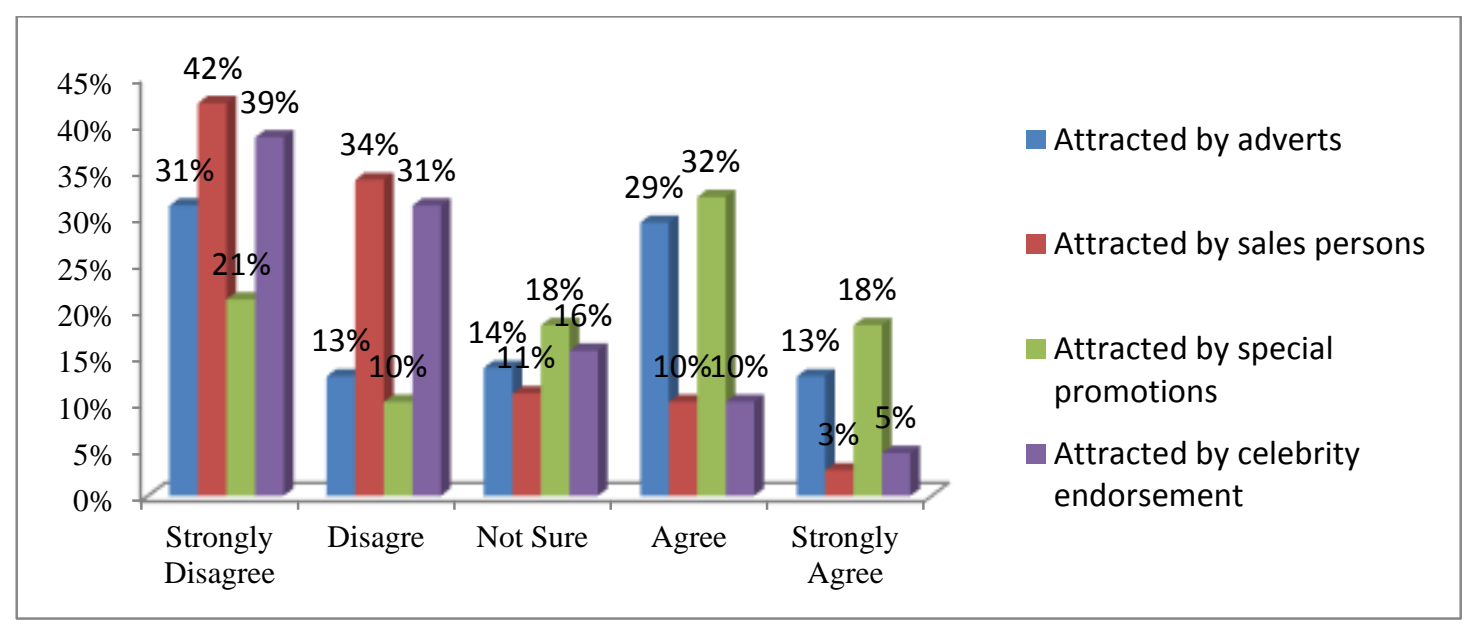

Fig. 11: Effects of advertisements/promotions on alcohol consumption 


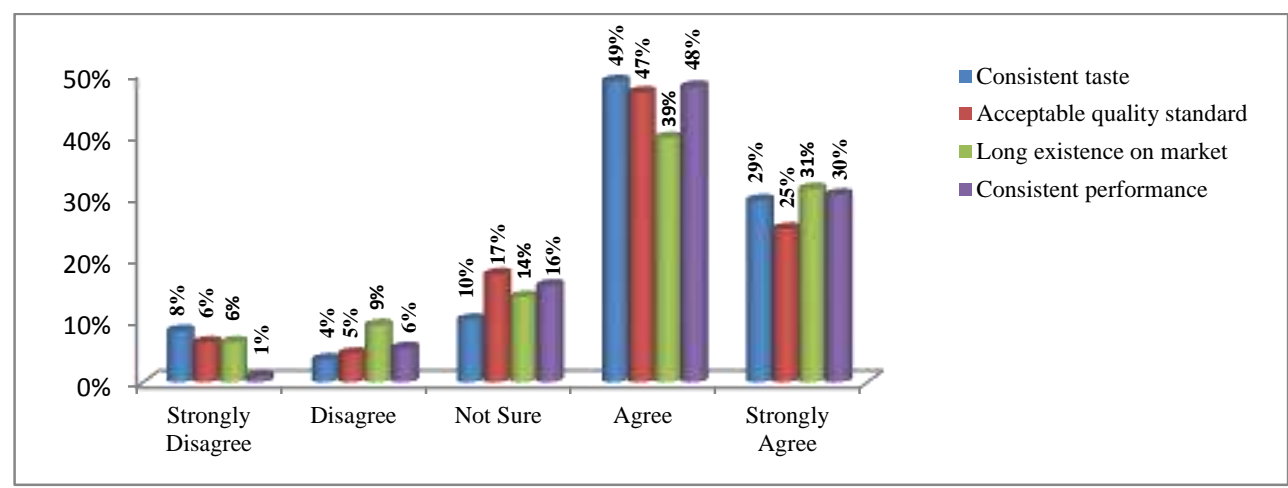

Fig. 12: Product/quality factors and alcohol consumption

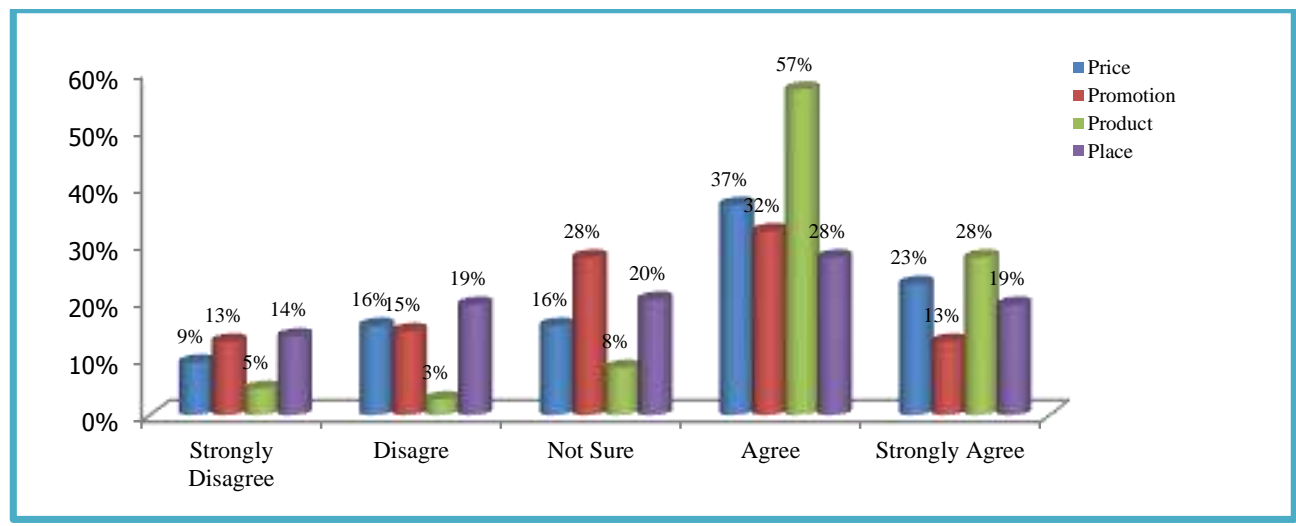

Fig. 13: Alcohol consumption and the marketing mix

About $44 \%$ of the students who reported alcohol consumption behaviour disagreed that their alcohol consumption behaviour is influenced by advertisements that are carried on different media channels. Similarly, the majority of students (78\%) who consume alcohol disagreed that their alcohol consumption behaviour is influenced by sales persons. Furthermore, about $70 \%$ disagreed that celebrity endorsement of particular brands of alcohol encourages them to purchase and consume alcohol. Nonethe-less, about $50 \%$ of them agreed that they are attracted by special promotions such as "buy one, get two" and "happy hours" when alcohol prices are slashed.

What this entails is that price discounts unlike bare advertisements without any price incentives are the ones that influence consumers to purchase and consume more alcohol. Students interviewed in FGD's also attested to the fact that special promotions such as the Carlsberg bash and others that announce price cuts attract them to consume more alcohol since they can afford the prices.

\section{Product mix}

The Product mix is the most dominant of the four P's in the Marketing Mix. Among others, some of the elements of the Product Mix are quality, features, accessories, product variety, brand name, services and packaging. In this study, elements such as taste, quality standard, product existence on the market and performance were considered.

Fig. 12 presents the level of agreement/disagreement towards these Product Mix elements in relation to the consumption of alcohol among students.
Most students agreed that their preferred alcohol brand has a consistent taste (78\%), has acceptable quality standard (72\%), has been on the market for long (70\%) and performs consistently (78\%). Students who took part in the FGDS had this to say in connection to the above Product Mix variables:

\footnotetext{
"We go for the brands with good taste and performance. We go for the beer that is strong in alcohol content. For example Carlsberg Green has got a good taste with more alcohol content than Kuchekuche. Also, it has survived the taste of time. Some beer come but do not last long".
}

This demonstrates that companies must think twice when developing their products in order to produce something that is going to meet customer satisfaction in terms of performance, taste and standards. These characteristics will make it easy for the products get sold to customers.

\section{Alcohol consumption and traditional Marketing Mix}

The marketing of products like alcohol has for a long time utilized the traditional marketing mix comprising product, price, place and promotion. If well blended, these factors can significantly influence the consumption of alcohol among students. Much as 4 P's have been separately dealt with in the foregoing, there is need to find out which among the P's appeals most among Malawian students when evaluating and making decisions about particular alcohol brands to purchase and consume.

Fig. 13 highlights the relative importance of each of the 4 P's of marketing in influencing students' alcohol consumption behaviour. 
The majority of students $85 \%$ agreed that the Product Mix of alcohol influences them to consume alcohol. Furthermore, $60 \%$ of the students agreed that the price of their preferred alcohol brand influences them to consume alcohol. Almost $45 \%$ of the students agreed that promotional activities attract them to consume alcohol.

The above findings suggest that the Product Mix is the most important aspect among the 4 P's that customers look upon when purchasing products. This is followed by the Price. As such, it is imperative for product producers to attend to the product that they intend to produce. It has to be made in such a way that the attributes within the product such as taste and performance in the case of alcohol satisfies the desire of customers. In addition, the price at which the product (alcohol) is offered should be reasonable. Having produced a good product (alcohol) and determined the right price, the promotion activities should be utilized to help publicise the product. In addition, the product should be made available to consumers in several outlets covering a wider area where target consumers are found.

According to the Theory of Reasoned Action, among the four P's (i.e. price, product features such as quality, performance) may lead students to change their attitude about alcohol and in turn positive attitudes about alcohol may lead to intentions to purchase and consume it.

\section{Areas for Future Research}

Areas that present prospects for future research are as follows:

- Are anti-alcohol campaigns among students that have been running across the world is having any impact on the marketing of alcoholic beverages in Malawi?

- To what the extent does religion have impact on the consumption of alcohol among youth?

\section{Conclusions}

The study has found that of the 138 respondents, 109 (79\%) consume alcohol. Of those who reported alcohol consumption $72 \%$ were males and $28 \%$ females. This difference in alcohol consumption between female students and their male counterparts could be explained partly by the traditional African attitude towards women and their role in the family and society. Traditionally, drinking among men is a sign of maturity and well-being and it is generally tolerated. On the other hand, alcohol consumption by women is socially unacceptable by many ethnic groups (Zverey, 2008). On specific factors that influence alcohol consumption among students the results were diverse and the account below provides a summary of what was found. Firstly, most students who take alcohol $(75 \%)$ agree that the price at which alcohol of their choice is sold matches the quality of alcohol. This implies that there is a direct relationship between price of alcohol, its quality and consumption. Thus, as long as quality of alcohol is good and reasonably priced, consumers will be willing to purchase and consume it.

On situational factors, the study found that students prefer to take alcohol in bars together with friends. This is so because there is more interaction with friends in bars unlike other drinking places.

The majority of students (74\%) disagreed that they drink alcohol because of their ethnic backgrounds or traditional beliefs. However, about $68 \%$ agreed that they take alcohol because their religion tolerates alcohol consumption.

The study has also shown that the majority of those who reported alcohol consumption are between 18-22 years of age. Perhaps this is so because peer influence since students transition from depending on their parents at home to depending on their peers on college campus (Borari and Carey, 2001 cited in Palmeri, 2011). Students also think that when they take alcohol they can easily be accepted by fellow peers who have the same behaviour.

In terms of the Place Mix, the study has found that students can take alcohol either on campus or off-campus. What matters is availability of alcohol of different brands wherever they choose to buy alcohol. For those who prefer taking alcohol off campus, they revealed that there are more outlets there than on campus. Due to competition for customers, some outlets offer alcohol at reduced prices which they can afford.

Most students (78\%) who reported alcohol consumption disagreed that their alcohol drinking behaviour is influenced by sales persons. In addition, $70 \%$ disagreed that they are influenced by celebrity endorsement of the alcohol of their choice. Nevertheless, $50 \%$ of those who reported alcohol consumption agreed that special promotions which focus on price cuts such as 'buy one get two' and 'happy hours' influence them to purchase more alcohol.

Among the traditional 4 P's of marketing, product features such as quality, consistent taste and performance influence their alcohol consumption behaviour. Respondents reported that consistent taste and good quality standard influence them to consume alcohol of their choice and the majority preferred Carlsberg Green beer.

\section{Recommendations}

Marketers and those companies engaged in the trading of alcohol should strive to design strategies that can increase uptake of alcohol among female students aged 18 and above since the study has shown that alcohol consumption among ladies is low. This might increase the sales volume of alcohol if marketing strategies targeting this segment of consumers are designed. In addition, companies should produce with quality that meets consumer expectations.

Since there is a direct relationship between price of alcohol and its quality, companies must work hard to produce alcohol of high quality in order to enlist demand from customers regardless of the price at which the alcohol is sold. 
In addition, the prices should be reasonable so that customers are not scared away.

Marketers have to attend to interpersonal relationships among students when designing their marketing strategies since they affect individual attitudes and intentions towards attainment of certain behaviours such as alcohol consumption.

It has also been established that students drink alcohol because it is tolerated in some religions. Marketers must therefore, attempt to analyse the religious atmosphere in the market segment where they wish to sell their alcohol.

Marketers should ensure that they design promotions that emphasise on price cuts and other offers such as buy one get two. This is so because this study has shown that mere advertisements will not lead one to purchase alcohol. Rather, the advertisements should portray benefits such as price reduction in order to enlist interest from students.

\section{References}

Asch P and Levy DT (1990) Young Driver Fatalities: The Roles of Drinking Age and Drinking Experience. Southern Economic Association. 57(2): 512-520. <Available from: http://www.jstor.org/stable/1060627> [Accessed 6 May 2013].

Association of Business Executives (ABE) (2008) Economic Principles and their Application to Business. Surrey, ABE.

Bergamaschi A et al. (1995) Cansumption, Behaviour and Knowledge with Respect to Alcohol Drinks in Student Nurses in the Province of Bologna, Italy. European Journal of Epidemiology 11(2): 185-191. Available from: http://www.jstor.org/stable/3582508> [Accessed 28 May 2013].

Brijball S (2003) The Level of Importance Attached to Price and Quality in Purchasing Behaviour. SA Journal of Industrial Psychology 29 (1): 93-99.

Christie J et al. (2001) The Effects of Bar-Sponsored Alcohol Beverage Promotions across Binge and NonBinge Drinkers. Journal of Public Policy and Marketing 20(2): 240-253. Available from: <http://www.jstor.org/stable/30000591> [Accessed 6 May 2013].

Department of Health and Human Services (1991) Youth and Alcohol: Controlling Alcohol Advertising that Appeals to Youth. Office of the Inspector General.

Frankie G and Wilcox G (1987) Alcohol Beverage Advertising and Consumption in the United States, 1964-1984. Journal of Advertising 16(3): 22-30. Available from: <http://www.jstor.org/stable/4188640> [Accessed 6 May 2013].

Freeman M and Parry C (2006) Alcohol Use Literature Review. Soul City

Hastings G et al. (2005) Alcohol Marketing and Young People's Drinking: A Review of the Research. Journal of Public
Health 26(3): 296-311. Available from: <http://www.jstor.org/stable/4125154> [Accessed 6 May 2013].

Keller KL (1993) Conceptualising, Measuring, and Managing Customer-Based Brand Equity. Journal of Marketing 57(1): 1-22.

Kotler P and Keller K (2012) Marketing Management. 14th Ed. Boston, Prentice Hall.

Kotler P et al. (1999) Marketing Principles. 2nd European Ed. London, Prentince Hall Europe.

Mandelbaum DG (1965) Alcohol and Culture. Current Anthropology 6(3): 281-293. Available from: <http:www.jstor.org/stable/2739922> [Accessed 28 May 2013].

Palmeri JM (2011) Peer Pressure and Alcohol Use among College Students. Available from: <http://steinhrdt.nyu.edu/opus/issues/2011/fall/peer > [Accessed 1 June 2013].

Pettigrew S and Donovan R (2003) A Literature Review of the Factors that Influence Alcohol Consumption and the Effectiveness of Past Interventions: A Report to the Drug and Alcohol Office. Government of Western Australia.

Ritter D (2008) Influential Factors on Brand Choice and Consumption Behaviours: An Exploratory Study on College Students and Beer. Master of Advertising Thesis, University of Florida.

Saunders M, Lewis P and Thornhill A (2009) Research Methods for Business Students. 5th ed. Harlow, Pearson Education Ltd.

Stafford J (1966) Effects of Group Influences on Consumer Brand Preferences. Journal of Marketing Research 3(1): 68-75. Available from: <http://www.jstor.org/stable/3149437> [Accessed 6 May 2013].

Stephenson N (2012). Increasing Cost of Alcohol Won't Stop Youth Drinking. Available from: $<$ http://www.aut.ac.nz/news/autnews/2012/march/increasing-cost-of-alcohol-wont-stopyouth-drinking>. [Accessed 3 May 2013].

Vallerand et al. (1992) Ajzen and Fishbein's Theory of Reasoned Action as Applied to Moral Behavior: A Confimatory Analysis. Journal of Personality and Social Psychology, 62(1): 98-109.

Wagenaar AC et al. (1974) Where and How Adolescents Obtain Alcoholic Beverages. Public Health Reports 108 (4): 459$464 . \quad$ Available from: <http://www.jstor.org/stable/4597417> [Accessed 6 May 2013].

World Health Organisation (2011). Global Status Report on Alcohol. Geneva, WHO.

Zverev Y (2008) Problem Drinking Among University Students in Malawi (2008) Coll. Anthlopol. 33(1): 27-31. Available from: http://www.ncbi.nlm.nih.gov/pubmed/18494185. [Accessed 27 August 2013]. 